disorder to unjust criminal justice proceedings which they cannot understand or fully participate in. Where an accused is deemed unable to do any one of these then he or she should be considered unfit to plead and can be dealt with under the Criminal Procedure (Insanity and Unfitness to Plead) Act 1991, usually by holding a trial of the facts and then, if convicted, considering disposal options such as a hospital order, supervision or an absolute discharge.

The fundamental principle of an individual's right to defend themselves should not be undermined without proper consideration. On the other hand, many professionals are of the opinion that the current system sets too high a threshold with the result that too few mentally disordered offenders are found unfit to plead. ${ }^{4}$ In the USA, around $10 \%$ of offenders are considered to 'lack competence to stand', but in England and Wales that figure is much lower. ${ }^{1}$ One of the reasons for this is that, strictly speaking, the current criteria focus almost exclusively on cognitive ability rather than decision-making capacity, with little account being paid to suggestibility, memory impairment, the ability to give evidence in court, the impact of psychosis or of cultural barriers.

In their report, the Law Commission propose a new legal test much more closely aligned with the capacity test recently enshrined in the Mental Capacity Act 2005. ${ }^{1}$ Under the new provisions an accused would need to demonstrate that they understood the information relevant to the decisions that he or she would have to make in the course of the trial, retain that information, use or weigh that information as part of the decision-making process and communicate his or her decisions. Such a test should be acceptable to psychiatrists, as it simplifies the requirements and largely mirrors the capacity test with which we are all now familiar. However, such a change could have significant cost and resource implications. The new system could see many more people assessed by psychiatrists and any corresponding increase in compulsory admissions could have a significant impact on forensic services, although the cost might be offset by a reduced number of custodial sentences. The Law Commission's final recommendations, expected later this year, are anticipated with great interest.

1 Law Commission. Unfitness to Plead (Consultation Paper No 197). Law Commission, 2010

$2 R \vee$ Prichard (1836) 7 C \& P 303

3 Akinkunmi AA. The MacArthur Competence Assessment Tool - Fitness to Plead: a preliminary evaluation of a research instrument for assessing fitness to plead in England and Wales. J Am Acad Psychiatry Law 2002; 30: $476-82$.

4 Rogers TP, Blackwood N, Farnham F, Pickup G, Watts M. Reformulating the law on fitness to plead: a qualitative study. J Forensic Psychiatry Psychol 2009; 20: 815-34.

Liz Tate, Specialty Registrar in Forensic Psychiatry, Wessex Deanery, Fareham, UK, email: liztate@doctors.org.uk

doi: $10.1192 / \mathrm{pb} .36 .4 .155 \mathrm{a}$

\section{Exposure to psychiatry in foundation years may improve recruitment and retention}

On reading the article by Barras \& Harris, ${ }^{1}$ I recognised one of the trainee's comments as my own. This comment was written merely weeks into my core trainee year 1 and related to the reaction of hospital consultants to my choosing psychiatry as a career (during my foundation 2 year, FY2). I would like to elaborate further on my experience as a foundation trainee in acute hospital medicine relating to psychiatry, and suggest what improvements could be made to the current system to boost recruitment and retention.

When I was an FY2 trainee, I was keen for the opportunity to undertake a 4-month rotation in psychiatry. Despite stating this preference, I was not allocated to the specialty and instead I completed FY2 jobs in accident and emergency, orthopaedics and intensive care. Although I was initially disappointed with this combination, it proved to be an extremely valuable learning opportunity which enabled me to realise and understand the vast overlap between psychiatry and acute hospital specialties. I observed trauma patients during my orthopaedic job who had sustained massive injuries from 'failed' suicide attempts. I saw numerous psychiatric presentations in the accident and emergency department. Even intensive care provided me with chances to understand the consequences of psychiatric illness, ranging from irreversible hypoxic brain damage following hanging in a patient with depression to endstage liver failure in a patient with alcohol dependence.

Many medical students and foundation doctors who have enjoyed the acute hospital setting during their foundation years may be reluctant to consider a specialty such as psychiatry. This may be particularly true if they have not worked in a psychiatric specialty during this time. Perhaps a solution would be to encourage deaneries to provide 3-month foundation posts instead of 4-month posts, so as more foundation doctors are exposed to psychiatry. It would also be worth considering whether these posts should be partly hospital based and have a particular emphasis on liaison psychiatry, so that foundation trainees can observe directly the important role of the psychiatrist in working collaboratively with medical colleagues. Barras \& Harris noted that $5.0 \%$ of trainees had stated they had considered leaving psychiatry because they wished they worked in a different specialty. ${ }^{1}$ At this time when retention rates are falling, perhaps enabling foundation doctors to see for themselves the diversity of psychiatry and how it integrates with acute hospital medicine is key.

1 Barras C, Harris J. Psychiatry recruited you, but will it retain you? Survey of trainees' opinions. Psychiatrist 2012; 36: 71-7.

Dineka Gray, CT3 trainee, Mersey Care NHS Trust, Liverpool, UK, email: dinekag@doctors.org.uk

doi: $10.1192 / p b .36 .4 .156$

\section{Revealing our religion/atheism in the witness box}

I gave evidence in a criminal court recently about one of my in-patients, with the patient watching from the dock. When the clerk asked me, 'Do you have a religion?', I answered 'No' and was given the words to read to make a solemn affirmation ('I do solemnly, sincerely and truly declare and affirm that the evidence which I shall give, shall be the truth, the whole truth and nothing but the truth'), rather than taking the oath ('I swear by Almighty God that the evidence... .') ${ }^{a}$ on a religious text. So

a. The Oaths Act 1978 directs that the oath/solemn affirmation shall start 'I swear by Almighty God that'/'I do solemnly, sincerely and truly declare and affirm that', 'followed by the words of the oath prescribed by law'. The words to follow cannot be found elsewhere in the Act, in another statute or in the rules of the court. In 1927 the King's Bench Judges approved the following form of oath for use in civil and criminal courts: 'the evidence, which I shall give, shall be the truth, the whole truth and nothing but the truth'. This is still in use today. 
far in my career, I have not chosen to share my lack of religious belief with any of my patients. This patient had recently had delusions with religious content. Knowing that I do not have a religion might have all sorts of implications for our therapeutic relationship. Also, the patient may tell the other patients on my ward, and the staff, with further potential implications for therapeutic and professional relationships.

Colleagues giving evidence in a civil or criminal court in the presence of one of their patients may wish to avoid such a disclosure. Although there is no way of giving oral evidence without making an affirmation or taking an oath (without risking contempt of court), I think if I was in a similar situation again I would let the clerk know in advance that I would like to make the affirmation. The clerk would then have no need to ask me about my religion and thus draw attention to my atheism in court.

This incident also made me wonder whether it is right that witnesses have to reveal their religion in open court before they can give evidence. Witnesses often do not have a choice whether to give evidence. 'Religious beliefs or other beliefs of a similar nature' are considered sensitive personal data in the Data Protection Act 1998 because their handling requires particular care, and cannot be 'processed' without special conditions being met. I cannot find any evidence whether rates of lying in court differ when the affirmation or the oath is used; in my opinion it is unlikely to make any difference. Perhaps the current oath system involves an unnecessary and unfair forced disclosure on the part of witnesses.

Catherine Penny, Locum Consultant Forensic Psychiatrist, Oxleas NHS Foundation Trust, UK, email: cpenny@nhs.net

doi: $10.1192 / \mathrm{pb} .36 .4 .156 a$

\section{Five simple questions to predict violence in psychiatric patients}

Forensic psychiatry is principally concerned with assessing and managing the risk to others (usually of violence) by people with a mental disorder. A variety of lengthy risk assessment instruments help consolidate this expertise, but these instruments do not find favour in day-to-day psychiatry.

Based on the work of Fazel and colleagues, ${ }^{1,2}$ we set out to determine whether five 'yes or no' questions (male gender; less than 32 years old; previous criminal convictions; and comorbid alcohol misuse and drug misuse) could predict later actual physical violence to others. We analysed case notes on consecutively discharged patients from a medium secure forensic unit (52 patients, 46 male); an out-patient addictions service (51 patients; 26 male); and a crisis resolution and home treatment service ( 25 patients, 17 male), in a 'pseudoprospective' method for a record of physical violence after applying these five questions as a screen to the case records 5 years earlier, from January 2006. Records with insufficient detail or length of history were excluded, and the screen was viewed as a positive predictor if three or more questions were answered 'yes'.

We found 30 (of 128) patients were violent in the 5 years studied, with $83 \%$ being predicted as violent by our screen (sensitivity), and a false negative rate of $17 \%$. The positive predictive value was poor at $38 \%$ but the negative predictive value (i.e. that a negative prediction was correct) was impressive at $92 \%$. The factors predicting later violence were being male (93\%); having a history of violence $(80 \%$, not a 'Fazel' question); a history of drug misuse (77\%); a prior criminal conviction (70\%); a history of alcohol misuse (60\%); poor treatment adherence (52\%, not a 'Fazel' question); and being less than 32 years old (50\%). A history of self-harm was only seen in $20 \%$ of those who were violent later.

The rates of 5 -year violence in the three separate groups were $35 \%$ in the forensic sample, $6 \%$ in addictions, and $36 \%$ in the acute community crisis resolution home treatment group. We acknowledge the preponderance of males in our sample will skew the results, given it is a screening question.

Our results raise two interesting points. First, that these five simple questions might aid clinical decision-making concerning which patients will not pose a risk of later violence, but does not elucidate prediction on who will become violent. This screen might therefore be useful as part of a stepped approach in a busy clinical environment when considering who to refer for more in-depth assessment. Second, as Turner \& Salter have already noted, ${ }^{3}$ we conclude it is hard to define who is 'a forensic patient' when we compare patterns across our three samples.

1 Fazel S, Långström N, Hjern A, Grann M, Lichtenstein P. Schizophrenia, substance abuse, and violent crime. JAMA 2009; 301: 2016-23.

2 Singh JP, Fazel S. 'Developing a violence screening instrument for patients with schizophrenia'. Paper presented at the XXXII International Congress on Law and Mental Health, Berlin, Germany, July 2011.

3 Turner T, Salter M. Forensic psychiatry and general psychiatry: re-examining the relationship. Psychiatrist 2008; 32: 2-6.

Mark Taylor is Consultant Psychiatrist, Ballenden House, NHS Lothian, Edinburgh, email: marktaylor2@nhs.net; Adam Groves, Fiona McCusker, Natalie Lee, Johanna Bradley, Gianluca Alonzi, Claire Murphy, Rebecca Miles, Samantha Ellis and Ellie Richardson are all medical students at the University of Edinburgh, UK.

doi: 10.1192/pb.36.4.157 